\title{
UM OLHAR SOBRE DUCHAMP E OLDENBURG
}

\author{
Janine Alessandra Perini \\ Universidade Federal Maranhão, Campus São Bernardo
}

\section{Resumo}

Este artigo pretende dar suporte para uma leitura em sala de aula do readymade Fontaine de Marcel Duchamp e Soft Toilet de Claes Oldenburg. Essas obras foram analisadas por meio de pressupostos da Semiótica Greimasiana, fazendo uso das teorias de Ana Claudia de Oliveira e das análises feitas pela crítica e historiadora Rosalind E. Krauss. Esta leitura fornece métodos de descrição, que permitem uma visão ampla da obra, com o intuito de aproximar o espectador para que possa apreciála esteticamente. Ao final das análises, foi verificado que as duas esculturas, mesmo tendo o tema em comum, têm suas diferenças, pois Duchamp apropria-se de objetos prontos e Oldenburg subverte a função do objeto, apresentando ao público formas amolecidas.

Palavras-chave: Leitura de imagem; Semiótica Greimasiana; Marcel Duchamp; Oldenburg.

\begin{abstract}
This article aims to provide support for a reading in the classroom ready made Fontaine Marcel Duchamp and Soft Toilet of Claes Oldenburg. These works were analyzed using assumptions of Greimas Semiotics, making use of the theories of Ana Claudia de Oliveira and analyzes made by the critic and historian Rosalind E. Krauss. This reading provides methods of description that allows a broad view of the work, with the aim of bringing the viewer to enjoy it aesthetically. At the end of the analysis, we found that the two sculptures, even having the common theme, have their differences, as Duchamp appropriates objects and ready Oldenburg subverts the function of the object, presenting to the public forms softened.
\end{abstract}

Key-words: Reading image; Greimasian semiotics; Marcel Duchamp; Oldenburg. 
O ensino da arte no Brasil, atualmente, está voltado à produção, à decodificação e à interpretação de imagens, buscando promover a formação artística e estética do aprendiz e a sua participação na sociedade. Com a afirmação de Sandra Regina Ramalho de Oliveira, podemos observar que a leitura da imagem ainda precisa ser melhor explorada em sala de aula:

\begin{abstract}
Muito se tem pensado sobre a produção da imagem; igualmente, muito se tem estudado sobre a história da imagem; no entanto, nem sempre é lembrado o que, à maioria das pessoas, talvez seja mais importante: a leitura da imagem. Isso implica em tornar o sujeito mais do que um mero espectador ou receptor, mas um enunciatário da imagem, isto é, um interlocutor que também produza significados, um leitor que de certa forma recrie a imagem. Os elementos estéticos estão aí, presentes no cotidiano de cada ser humano; cabe então compreendê-los (OLIVEIRA, 1999, p.1).
\end{abstract}

Este artigo pretende dar suporte à leitura da imagem das obras Fontaine de Marcel Duchamp e Soft Toilet de Claes Oldenburg. A análise das obras, realizada a partir de fundamentos da semiótica, proposta pelas teorias do francês Algirdas Julien Greimas, pretendem dar conta do fenômeno da produção de sentido. Para ele, o principal objetivo de sua teoria é o de estudar "o discurso com base na idéia de que uma estrutura narrativa se manifesta em qualquer tipo de texto" (NÖTH, 1996, p.145).

A palavra semiótica vem do grego, semeion, que significa signo e estuda a significação. Semiótica para Nöth é a "ciência dos signos e dos processos significativos (semiose) na natureza e na cultura" (NÖTH, 1995, p.17). Inspirado em Algirdas Julien Greimas, a semiótica para R. Odin é "teoria geral dos sistemas de comunicação, capaz de possibilitar o estudo do conjunto dos processos de produção de sentidos, seja intervindo nas linguagens verbais, não verbais ou no mundo natural" (ODIN, apud Ramalho e Oliveira, 1990, p.16).

A Semiótica Greimasiana teve sua origem com as teorias do suíço Ferdinand de Saussure (1857-1915), que propôs o termo Semiologia para designar o estudo geral de todos os sistemas de signos, enfatizando o estudo das línguas naturais. Depois, o dinamarquês Louis Hjelmslev (1899-1965) propôs critérios para considerar outros sistemas que não os das línguas naturais. Foram dele as expressões e conceitos "plano de expressão" (significante) e "plano de conteúdo" (significado). Mais tarde, o francês Roland Barthes (1915- 1980) agrega a noção de sujeito e o sentido cultural ao processo de significação.

Os estudos de Greimas na área da Semiótica surgiram depois desses estudiosos, mas foram tão relevantes que essa linha recebeu seu nome. A partir dele, surgiram alguns 
discípulos como Eric Landowski, Jacques Fontanille e Jean - Marie Floch. Floch foi um dos primeiros a se dedicar às imagens visuais e também teve seus herdeiros teóricos, como Andrea Semprini e a brasileira Ana Cláudia de Oliveira.

Um dos médotos utilizados na Semiótica para produção de sentido é o Percuso Gerativo de Sentido, que permite uma visão ampla de vários ângulos para propiciar uma melhor apreensão de sentidos de um texto, seja uma imagem fixa ou móvel, poesia ou até mesmo as línguas naturais.

Segundo Fiorin (2005), a visão única permite somente a parcialidade, tornando-se disfórica, ou seja, mostra efeitos de sentidos parciais. Ao passarmos por diversos pontos de vista, visamos a totalidade, que pode ser eufórica e positiva, ou seu contrário, disfórica; ou os seus significados podem ainda se apresentar como uma composição de sentidos nos quais se apresentam efeitos disfóricos e eufóricos. Essa produção de sentido do texto ocorre do mais simples e profundo ao mais superficial e complexo. Nessa caminhada passamos do mais simples (o todo) em direção ao mais complexo (análise das partes), permitindo um conhecimento mais aprofundado ao que está sendo analisado.

Nessa caminhada, do Percurso Geartivo de Sentido, participam os seguintes elementos: o enunciador, ou seja, quem produz ou o autor da enunciação; o enunciado, ou seja, o texto ou a mensagem; o enunciatário, ou seja, o destinatário. Sandra Ramalho de Oliveira, nos alerta que:

\begin{abstract}
O enunciatário é, neste sentido, mais do que um destinatário passivo do texto, por ser também um gerador de efeitos de sentido, do mesmo modo que o enunciador o é. Este é um conceito de Greimas muito caro para o estudo das imagens no contexto do ensino da arte: não há uma espécie de superioridade do produtor do texto, pois ambos os pólos da semiose, ou ambos os sujeitos da comunicação, enunciador e enunciatário, são, do mesmo modo, produtores de sentidos (OLIVEIRA, 2011, p.94).
\end{abstract}

No Percurso Gerativo de Sentido, também participam os elementos constitutivos do plano de expressão que advêm da enunciação e o plano de conteúdo que é a compreensão de todos os elementos produzindo o sentido, gerando o significado que fazem parte do enunciado. Plano de expressão e plano de conteúdo são duas dimensões do texto ou do enunciado que são indissociáveis, exceto para efeitos de análise, inexistindo uma hierarquia entre eles.

Esse método é embasado em três níveis: o fundamental, o narrativo e o discursivo, tendo cada qual seu componente sintáxico e componente semântico. No componente sintáxico, percebemos as partes com suas relações abstratas, gerando significado. No 
componente semântico, processam-se as relações numa sucessão de investimentos mais concretos, o que é o significado propriamente gerado.

Desse modelo derivam vários outros. Para Oliveira, A. (2004), a semiótica fornece métodos de descrição da pintura, na mesma medida em que ela nos fornece meios para melhor apreciá-la e, assim, nos aproximarmos esteticamente dela. Para a autora, a linguagem pictórica constrói-se a partir do plano de expressão e do plano de conteúdo. $O$ plano de expressão trabalha a relação entre as partes que compõem uma imagem ou texto. O significado alcançado por meio dessa relação é o plano de conteúdo. O olhar vai e vem nessa perspectiva de ver o todo a partir das partes que o compõem e vice-versa.

A descrição de uma obra para Oliveira, A. (2004) é denominada de formantes pictóricos, que possuem uma natureza composta por certas dimensões. A dimensão cromática, que constitui a cor; a dimensão eidética, que constitui a forma; a dimensão matérica, que constitui os materiais, técnicas e procedimentos e a dimensão topológica, que se concretiza pela combinatória das anteriores em um dado espaço-suporte.

A partir da Semiótica Greimasiana, utilizando as teorias de Ana Claudia Oliveira, serão analisadas as obras Fontaine de Marcel Duchamp e Soft Toilet de Claes Oldenburg, pois como disse Lucia Teixeira, para ler o texto visual deve-se ir além de observar linhas, volumes e cores, é preciso adotar uma metodologia para analisar os sistemas semisimbólicos. "O conceito de linguagem semi-simbólica foi proposto por Greimas e Courtés a partir da noção hjelmsleviana de linguagens monoplanas ou sistemas de símbolos. Os símbolos são estruturas interpretáveis como grandezas isomorfas à interpretação, são portadores de um sentido de conteúdo (...)" (TEIXEIRA, 2008, p.5). Para a autora, a forma de expressão é relacionada à forma de conteúdo e a interpretação dos símbolos estão condicionados à correlação entre essas duas formas.

A leitura da obra proporciona uma interpretação dos símbolos estéticos utilizados pelo enunciador, sendo realizada com o olhar específico do enunciatário, no caso, nós como observadores da obra. "Caberá ao enunciatário, com os seus referenciais e do seu meio, atribuir significados aos efeitos que a imagem oferece a ele" (OLIVEIRA,S., 2007, p.189).

Essa leitura da obra é uma ferramenta para perceber a obra de arte e não apenas vê-la. Perceber é interpretar, compreender o que enxergamos e essas percepções como Oliveira,S. (2007) nos escreve, são formadas com os referenciais do leitor, por nossas crenças, religiões, filosofias; aquilo em que acreditamos exerce um enorme controle sobre aquilo que vemos. 
Outra autora que tem o mesmo pensamento é Mc Fee (1964). Sua teoria é baseada em uma visão antropológica e sociológica do ensino das artes visuais e para a autora a percepção varia de acordo com o contexto cultural do aluno, pois a cultura influencia a direção do seu treinamento perceptual, dando-lhe muito mais oportunidades e recompensas por observar as coisas que são importantes para o seu grupo do que por observar aquilo que não é enfatizado pela cultura desse grupo.

Olhar-se-á como a imagem se mostra, o que mostra para compreender o que significa, pelos modos de sua estruturação textual. A compreensão visual é o meio natural que não precisa ser aprendido, mas apenas refinado por meio do alfabetismo visual. Para Ana Claudia de Oliveira "educar é, sem dúvida, fazer ver mais, ver além das aparências que vestem as coisas e os discursos, o que se processa através da compreensão das relações produtoras de significação" (OLIVEIRA, 1998, p. 10).

Educar é transformar o enunciatário em observadores menos passivos, elevando a capacidade de avaliar acima da aceitação (ou recusa) meramente intuitiva de uma obra de arte. Educar é dar sentido àquilo que vemos. Floch (1985) diz que:

O sentido nasce de diferenças que é preciso detectar para construir um sistema de relações; o sentido é o resultado de um 'percurso gerativo' que vai das articulações mais simples, que fundam a inteligibilidade, àquelas, complexas, que organizam a 'superfície' do que se convencionou então chamar o texto - mesmo que se trate de um filme, de uma dança ou de um quadro, e não de uma obra literária (FLOCH, 1985, p.75).

Para o autor, esse sentido que nasce pela diferença pode ser encontrado na leitura das obras de arte pelos contrastes plásticos, Lúcia Texeira explica:

Segundo Floch, a pesquisa sobre os sistemas semi-simbólicos foi estimulada por aquilo que os pintores chamam contrastes plásticos, ou seja, a co-presença, numa mesma superfície, de dois termos contrários de uma categoria. A observação de tais contrastes, que podem tanto realizar-se como simples oposição binária, quanto obedecer a uma série de combinações e superposições, encaminha a análise para uma primeira descrição, que observará sistemas semi-simbólicos realizando-se seja sobre apenas uma categoria da expressão, seja sobre uma hierarquia de categorias, seja ainda sobre uma verdadeira redundância do significante (TEXEIRA, 2008, p.6).

Agora, tentaremos produzir sentido às obras Fontaine de Marcel Duchamp e Soft Toilet de Claes Oldenburg, vendo o todo a partir das partes que as compõem e vice-versa.

\section{Duchamp e um objeto (extra) ordinário}


No mínimo é estranho encontrar um mictório em um pedestal numa galeria de arte. O efeito disso faz com que o observador concentre sua atenção na estranheza do objeto. Um objeto utilitário do contexto real, visto num contexto pictórico. Isso já vem sendo discutido desde 1919, quando Freud (1970) descarta as categorias estéticas tradicionais para propor em seu lugar "O estranho". Para ele, o estranho é ao mesmo tempo familiar e inquietante, remetendo ao que deveria ter ficado à sombra, mas veio à luz. Estamos diante de "Fontaine" de Marcel Duchamp (1887 - 1968).

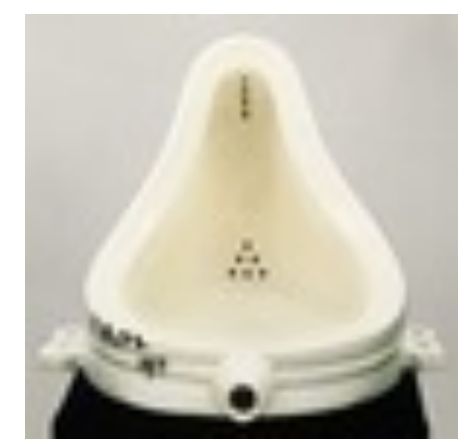

Fig. 1- Duchamp, Marcel, Fontaine, 1917.

Fonte da imagem: http://www.centrepompidou.fr/cpv/rechercher.action\#back.

Com acesso em 10 de setembro de 2013.

A obra Fontaine, que podemos observar na Figura 1, foi criada por Marcel Duchamp em 1917. A obra original foi perdida e sua réplica foi feita de acordo com a fotografia original, tomada em 1917 por Alfred Stieglitz, e conduzida sob a direção de Marcel Duchamp, em 1964 para a galeria Schwarz, em Milão. Atualmente, a obra se encontra no Centro Georges Pompidou, em Paris, França.

No Centro Pompidou, em 6 de janeiro de 2006, a obra sofreu um ataque de vandalismo,com escoriações leves, por um francês de 77 anos que a atacou com um martelo. Esse senhor, em seguida, foi detido e alegou que o ataque com o martelo era uma performance artística e que o próprio Marcel Duchamp teria apreciado tal atitude.

Fontaine é uma obra Dadaísta, um dos movimentos mais importantes do início do século XX. O Dadaísmo iniciou em 1916, com uma arte provocadora, realizada por artistas que estavam inquietos com os horrores da Primeira Guerra Mundial.

Toda tentativa de gerar uma demanda fundamentalmente nova, visando à abertura de novos caminhos, acaba ultrapassando seus próprios objetivos. Foi o que aconteceu com o dadaísmo, na medida em que sacrificou os valores de mercado intrínsecos ao cinema, em benefício de intenções mais 
significativas, das quais naturalmente ele não tinha consciência, na forma aqui descrita. Os dadaístas estavam menos interessados em assegurar a utilização mercantil de suas obras de arte que em torná-las impróprias para qualquer utilização contemplativa. Tentavam atingir esse objetivo, entre outros métodos, pela desvalorização sistemática do seu material. Seus poemas são "saladas de palavras", contêm interpelações obscenas e todos os detritos verbais concebíveis. O mesmo se dava com seus quadros, nos quais colocavam botões e bilhetes de transito. Com esses meios, aniquilavam impiedosamente a aura de suas criações, que eles estigmatizavam como reprodução, com os instrumentos de produção. Impossível diante de um quadro de Arp ou de um poema de Aguste Stramm, consagrar algum tempo ao recolhimento ou à avaliação, como diante de um quadro de Derain ou de Rilke. Ao recolhimento, que se transformou, na fase da degenerescência da burguesia, numa escola de comportamento anti-social (sic.), opõe-se a distração, como uma variedade do comportamento social. O comportamento social provocado pelo dadaísmo foi o escândalo. $\mathrm{Na}$ realidade, as manifestações dadaístas asseguravam uma distração intensa, transformando a obra de arte no centro de um escândalo. Essa obra de arte tinha que satisfazer uma exigência básica: suscitar a indignação pública. De espetáculo atraente para olhar e sedutor para o ouvido, a obra de arte convertia-se num tiro. Atingia, pela agressão, o espectador. E com isso esteve a ponto de recuperar para o presente a qualidade tátil, a mais indispensável para a arte nas grandes épocas de reconstrução histórica (BENJAMIN, 1994, p.191).

Uma arte que não queria agradar o espectador, questionando os valores tradicionais e a própria instituição de arte. Alguns trabalhos e projetos introduziram novos conceitos à arte, como o "acaso" e a "escolha" para libertar as pessoas do pensamento lógico e racional.

Algumas obras de arte dadaístas estabelecem a relação de objetos com a experiência da vida cotidiana, chamadas de readymades, que significa confeccionado, pronto e a expressão foi criada em 1913, pelo artista francês Marcel Duchamp para designar qualquer objeto manufaturado de consumo popular, tratado como objeto de arte por opção do artista, como podemos confirmar com a fala do artista no livro da Taschen:

Em 1913 eu tive a feliz ideia de fixar uma roda de bicicleta a um banco de cozinha e ficar a vê-la rodar. Alguns meses depois, comprei uma reprodução barata de uma paisagem de entardecer de inverno, que denominei de "Farmácia", após the acrescentar duas pequenas manchas, uma vermelha e uma amarela, no horizonte. Em Nova Yorque, em 1915, comprei numa loja de ferragens uma pá para a neve na qual eu escrevi "em antecipação ao braço partido". Foi por essa altura que a palavra readymade me veio ao espírito para designar esta forma de manifestação. Um ponto que eu desejo frisar é que a escolha destes readymades nunca foi ditada por deleite estético. A escolha baseou-se numa reacção de indiferença visual e, em simultâneo, com uma total ausência de bom ou mau gosto... (KÖLN, TASCHEN, 2005: 457).

Antes dos readymades de Marcel Duchamp ainda era possível pensar nas obras de arte como pertencentes a uma de suas amplas categorias: a pintura e a escultura. Depois, 
houve uma decomposição das certezas desse sistema de classificação, principalmente depois de 1960, as obras desafiam as classificações habituais e colocam em questão a própria definição de arte. Interpelam criticamente o mercado e o sistema de validação da arte.

Duchamp escolhia objetos fabricados em série, apropriava-se deles, deslocava-os e resignificava-os. O artista faz o observador formular questões, fazendo-o pensar: o que define a singularidade da obra de arte em meio à multiplicidade de todos os outros objetos? Duchamp afirma que os objetos não possuem um valor em si, mas que o adquirem em função do juízo de um sujeito e da avaliação conferida a eles pela definição de uma autoria.

Fontaine era um mictório comum que Duchamp girou noventa graus. O que antes era conectado à parede ficou sendo a base do readymade. Essa nova posição Duchamp assinou com um pseudônimo e datou: "R. Mutt, 1917". A assinatura entrou na obra e interferiu nela. Como Ana Claudia Oliveira já colocou "(...) a assinatura do pintor é um dos seus modos de presença na tela" (OLIVEIRA, A. 2004, p. 129). Para Duchamp, o trabalho deixaria de ser um objeto comum, pois sofrera uma transformação. Assim, esse objeto foi transferido do mundo comum para o mundo das artes.

Fontaine fez sua entrada no mundo da arte, se tratava essencialmente de
uma obra de arte no sentido puramente institucional do termo. Ela não era
uma na acepção genérica do termo (a classe dos urinóis era mais
impregnante para ela do que a classe das esculturas), nem na acepção
genética (Duchamp não havia criado o urinol), nem na acepção semiótica
(os sanitários não são suportes semióticos autônomos), nem na acepção
funcional (as qualidades estéticas do urinol não eram qualidades estéticas
de Fontaine). Ela foi uma obra na medida exata em que Duchamp chegava
a impor seu desafio ao mundo da arte, ou seja, na medida exata pela qual
ele chegava a impor o "batismo" artístico do urinol em questão (SHAEFFER,
2004, p.67).

Fontaine, como todas as manifestações tridimensionais, deveria ser analisada de todos os ângulos, sendo olhada de frente, de perfil, de costas, de todos os lados. Como estamos fisicamente distantes da obra, resta-nos analisar a imagem da obra que encontramos no site do Centro Pompidou. Essa obra será analisada pela semiótica Greimasiana, com seus dois planos, o plano da expressão e o plano do conteúdo, que somente reunidos produzem a significação. O plano da expressão representa o significante, ou seja, as qualidades sensíveis da imagem, suas cores (dimensão cromática), formas (dimensão eidética), materialidade (dimensão matérica) e sua disposição no espaço (dimensão topológica). O plano do conteúdo representa o significado, o tema, o discurso. 


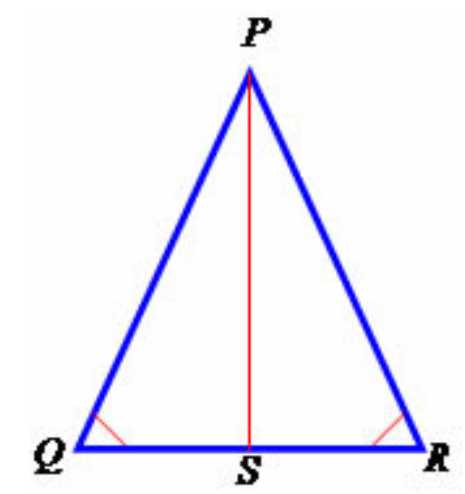

Fig.2- Escaneamento visual para desconstruir a obra Fontaine

Ao observar a imagem por meio de um escaneamento visual, identificamos a estrutura básica da imagem em forma de um triângulo como podemos notar na Figura 2. $\mathrm{O}$ triângulo é um dos polígonos mais simples da Geometria, em relação ao número de lados e ângulos. São três lados e três ângulos. Esse triângulo que visualizamos, olhando a obra Fontaine, identificamo-lo como Triângulo Isósceles, que tem como base dois lados iguais e um diferente, sendo o lado diferente a base do triângulo. Se mentalmente traçarmos uma linha vertical unindo o vértice do triângulo ao ponto médio da base dele, que no escaneamento visual chamei de P e S, respectivamente, dividiremos a obra em duas partes e conseguiremos visualizar a altura da obra e perceberemos que essas duas partes são iguais, tornando a obra de arte simétrica.

Analisando a obra pelas dimensões que Ana Claudia Oliveira propõe, podemos verificar que na dimensão cromática a escultura é da cor branca, pura e brilhante. Visualmente tem um jogo de luz e sombra, criado por ser tridimensional, sendo observadas, assim, as oposições do tipo luminoso e sombrio.

$\mathrm{Na}$ dimensão eidética, podemos observar o predomínio de linhas curvas, que deixam a escultura com forma arredondada. As curvas dão volume para a obra tridimensional, que é posicionada verticalmente. $\mathrm{Na}$ frente, na parte inferior da base do objeto, há um orifício em forma de cilindro, onde se percebem dois furos. Nessa base encontramos uma linha curva que segue o formato do objeto, que se situa bem no meio, entre a linha superior e a linha inferior da base. Ainda na base, mas agora nas laterais, deixando a obra simétrica, existe uma forma em cada lado com dois furos também, remetendo-nos a uma nadadeira de peixe ou alça de uma baixela. Os furos também são encontrados na parte vertical, logo em cima da base. Em forma de triângulo, existem seis furos e em sua direção mais para cima em linha reta há mais quatro furos colocados verticalmente. 
Na dimensão topológica, a forma curvilínea tem uma postura ereta, obtida num eixo vertical perpendicular ao suporte de base. Seu equilíbrio é obtido pela inércia do corpo, atestando sua força energética. O ponto central da obra são os seis furos em forma de triângulo, perto da base escultórica. A obra tem a textura lisa, escorregadia e gelada, mas na base por causa da linha do meio que separa a linha superior da inferior, percebemos uma textura ondulada. As combinações de linhas e volumes concretizam-se em contraste com o côncavo e o convexo.

$\mathrm{Na}$ dimensão matérica, Fontaine é de porcelana e mede $61 \mathrm{~cm}$. Ela não traz à superfície só o mundo da arte, mas também o mundo da vida, do cotidiano. E isso faz com que contrastemos o objeto único (Fontaine) com múltiplos objetos (mictório).

Roslind E. Krauss (1998) coloca que podemos perceber um subtexto erótico, que se fixa ao objeto por intermédio do trocadilho visual sugerido pela nova posição do objeto. Essa posição sugere a forma uterina, e a sua superfície as curvas implícitas do corpo feminino. Krauss analisa essa relação entre o torso nu feminino e a forma do mictório invertido como uma metáfora. Assim, Fontaine não parece ter sido fabricada por Duchamp, mas sim pelo observador que tem a necessidade de encontrar um significado nas obras de artes. E ela acrescenta:

\footnotetext{
A estratégia de Duchamp foi apresentar um trabalho que a análise formal não possa reduzir, um trabalho que esteja desvinculado de seus sentimentos pessoais e que não ofereça nenhuma resposta aos nossos esforços em decodificá-lo ou compreendê-lo (KRAUSS, 1998, p.98).
}

Num sentido que considera a fatura como manualidade, pode-se dizer que essa obra não foi feita por Duchamp, mas foi selecionada por ele. O artista escolheu um objeto entre tantos produtos industrializados, não pelo objeto físico e sim para formular questões, fazer o observador pensar. Ao fazer isso, colocou um novo problema nas considerações do que seja uma obra de arte.

\section{Oldenburg e um objeto-corpo}

O escultor norte-americano de origem sueca, Claes Thure Oldenburg (1929) também utilizou como tema de sua obra os objetos do cotidiano, misturando a arte e a vida. Esse artista trabalha com materiais inusitados em suas esculturas, que normalmente são realizadas em grande escala. 
Na década de 60, Oldenburg envolveu-se com o movimento da Pop Arte, que tinha como desejo bombardear seus espectadores com um excesso de coisas e acontecimentos sobre os quais as pessoas não tinham mais controle. Os artistas Pop davam novas interpretações e significados ao utilizarem imagens e objetos do dia-a-dia.

Esse movimento artístico teve início principalmente nos Estados Unidos e na Inglaterra, com influências principalmente do Surrealismo, Dadaísmo e do Expressionismo Abstrato. A desestabilização na sociedade depois da Segunda Guerra Mundial, o bombardeamento de informações por parte dos meios de comunicação, o entusiasmo pelas novas tecnologias, o excessivo consumismo do capitalismo, influenciaram os artistas da época a produzir uma arte crítica à realidade vivida pela humanidade.

A obra Soft Toilet faz parte das esculturas moles de Oldenburg, onde os objetos recebem um outro sentido. Para Oldenburg somos a imagem dos objetos que nos rodeiam. "Estas são as minhas coisas- os objetos que eu uso diariamente; e eu me pareço com eles" (KRAUSS, 1998, p. 274).

A obra atualmente encontra-se no Whitney Museum of American Art, em Nova York, Estados Unidos. Esse museu tem como objetivo recolher, conservar, interpretar e expor a arte americana, com um foco especial em obras de artistas vivos.

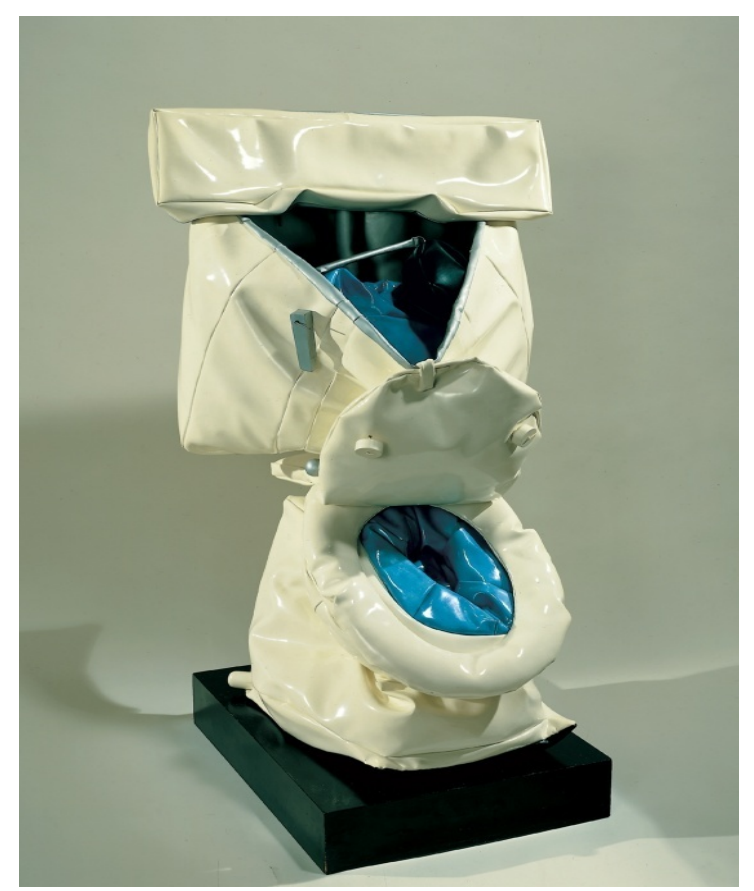

Fig. 3 - Oldenburg, Claes. Soft Toilet, 1966.

Fonte da imagem: http://whitney.org/Collection/ClaesOldenburg/7983ab. Com acesso em $10 \mathrm{de}$ setembro de 2013. 
Assim como Fontaine, Soft Toilet, datada de 1966, também deveria ser analisada de todos os ângulos, olhando de frente, de perfil, de costas, de todos os lados, mas é necessário contentar-se com essa imagem da Figura 3, retirada do site do museu de arte americana. Olhando a obra rapidamente, vemos um sanitário mole em cima de um pedestal preto, com tampa e uma descarga, que é fixada por um suporte prateado em forma de cilindro. A descarga está aberta por um zíper prateado. Deve-se olhar a obra com um olhar mais curioso, como Buoro (2003) enfatiza: o tempo de observação de uma obra além do olhar-minuto, vamos tentar analisar a obra na sua complexidade.
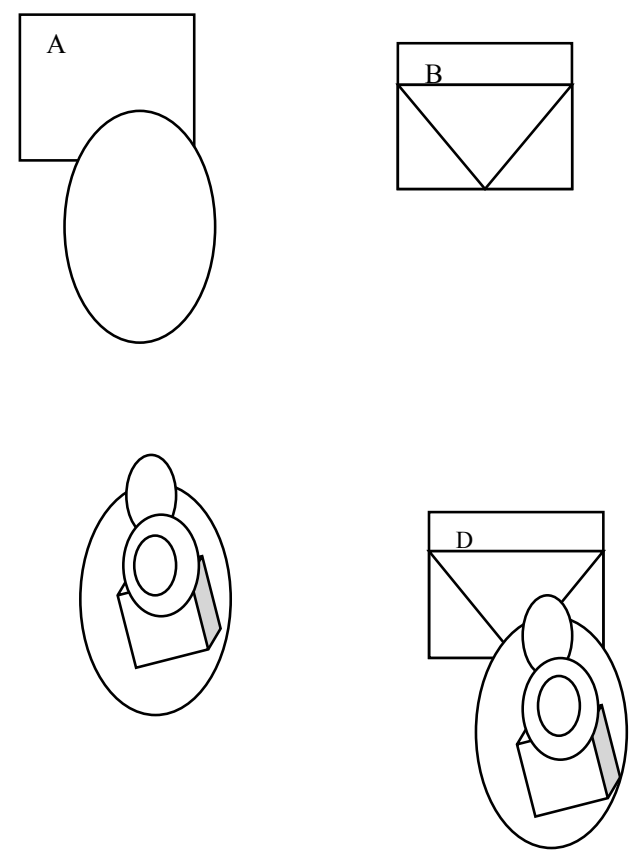

Figura 4- Escaneamento visual para desconstruir a obra Soft Toilet

No escaneamento visual, identificamos primeiramente a estrutura básica da obra de arte em duas formas geométricas, uma em cima e a outra em baixo como podemos observar na Figura 4, parte A. Em cima um retângulo, cujos lados formam ângulos retos entre si e que, por isso, possui dois lados paralelos verticalmente e os outros dois paralelos horizontalmente. O retângulo é um paralelogramo cujos ângulos são retos. Na obra Soft Toilet, dentro desse retângulo, podemos observar outras formas geométricas, como podemos observar na Figura 4, parte B. Uma é um retângulo formado pelo lado horizontal de cima do retângulo maior e as outras formas são criadas pelo zíper aberto. Essas formas criadas pelo zíper aberto são três triângulos, onde podemos ver dois e imaginar a formação do terceiro. 
A forma geométrica de baixo é em forma oval. Dentro do oval maior podemos observar outros menores criados pelo acento do vaso, como se pode observar na Figura 4, parte C. Um oval é criado pelo azul que representa a água, o outro é criado pelo acento e outro pela tampa. Essa forma remete à noção de ovo, o que propõe muitos significados como ninho, origem de vida, maternidade e também pode ser uma figurativização de orifício, um buraco. Essas três formas ovais menores estão sobre uma forma indefinida, mas de linhas retas, que dão certa sustentabilidade a essas formas ovais.

Pensando na estrutura básica da obra em um todo, como se observa na Figura 4, parte $D$, são várias formas geométricas, uma dentro da outra ou uma que dá a base para a formação de outra. Essas formas geométricas agrupadas conferem uma tensão, que faz com que observemos a obra com certo estranhamento e interesse, por isso serão analisadas mais detalhadamente.

$\mathrm{Na}$ dimensão cromática, a maior parte da escultura é da cor branca, pura e brilhante. O título Soft Toilet remete-nos ao branco puro, gelado que faz lembrar um banheiro, um fantasma. Visualmente, tem um jogo de luz e sombra, criado pelas dobras do material. Observado, assim, as oposições são do tipo cheio e vazio. O objeto tem um suporte preto e alguns pontos metálicos, como o zíper da descarga, o cilindro que dá sustentabilidade à descarga e os parafusos que seguram a tampa do sanitário. Dentro do vaso também encontramos a cor azul, simbolizando a água limpa. A cor fria, como o azul, têm a propriedade de tornar o objeto menor, isso ainda é exaltado pelo objeto ser tridimensional, onde as formas vão se fechando criando a profundidade, que é realçada com o escuro que é dado com a sombra. Esse escuro nos remete ao buraco que escrevemos acima, sugerido pela forma oval.

Na dimensão eidética, podemos observar o predomínio de linhas retas no suporte e na descarga, mas no sanitário verifica-se o predomínio de linhas curvas, como podemos notar no escaneamento visual. $\mathrm{Na}$ estrutura básica da escultura observam-se figuras geométricas regulares, os retângulos com linhas retas paralelas, os triângulos que estão dentro do retângulo que podem ser observados na Figura 4, B com linhas retas ascendestes e descendentes e o oval com linhas curvas, que podem ser observados na Figura 4, C. As linhas retas dão uma sensação de equilíbrio à obra, um equilíbrio oculto, que não faz cair toda a estrutura mole, que as linhas curvas fazem pensar que é. As linhas curvas tencionam, dão movimento, sugerem leveza, sensualidade.

Na dimensão topológica, podemos verificar o ponto de interesse da obra, que é a descarga com o zíper aberto e o azul que simboliza a água do vaso sanitário. A escultura, 
com a textura mole, flexível e macia, contrasta com o suporte e o cilindro, dando sustentabilidade à descarga. São duros, rígidos, mas todos são lisos e brilhantes. A obra possui uma postura ereta, obtida num eixo vertical, que a torna equilibrada e simétrica. Suas formas são claras e ousadas e as combinações de linhas e volumes concretizam-se em contraste com o côncavo e o convexo.

Na dimensão matérica, a obra é feita de lona pintada, forrada com paina e madeira. Mede 129,5 cm x 83,82 cm x 71,12 cm. A obra está em cima de um suporte em forma de quadrado, na cor preta.

Para Krauss (1998), a obra promove um sentido de interação, em que o observador é um participante, sendo a massa dos objetos construída em termos que sugerem o corpo do observador, flexível e macio, como sua carne. Faz o observador pensar que ele se parece com os objetos que utiliza diariamente. Ela afirma que com Oldenburg o tom se torna sardônico:

Embora suavizada e velada pela ironia, a relação do trabalho de Oldenburg com sua platéia é de agressão. A maciez das esculturas abala as convenções da estrutura racional, e suas associações, para o observador, atacam os pressupostos deste de que ele é o agente conceitual do desenvolvimento temporal do evento (KRAUSS, 1998, p.276).

A autora afirma que a obra Soft Toilet é uma agressão ao enunciatário. Pode-se aceitar facilmente essa quebra da estrutura racional ou lembrar de Freud (1970), no "estranho", objeto ao mesmo tempo familiar e inquietante. Soft Toilet gera um incômodo visual e espacial, perturbando o enunciatário, tornando a obra de arte um objeto carregado de questionamentos, como Hiromoto (2004) afirma:

\begin{abstract}
A intensa manipulação dos objetos geraria um incômodo visual e espacial no homem. Nas esculturas carregadas de questionamentos, a busca da aproximação com a dimensão humana - em que formas aliam-se a sentimentos, a jogos de linguagens, às imagens, ao afeto, próximo a corpos e rostos -, tomaria traços antropomórficos. Esse antropomorfismo que Oldenburg apresenta em suas obras baseia-se em apropriar-se de objetos industrializados, transformando-os para dar-Ihes uma conotação sensual através da referência a uma região do corpo. São objetos diversos, como tomadas, canos de esgoto, vaso sanitário, entre outros. A produção destas esculturas teria o intuito de evidenciar o aspecto erótico e ampliar os horizontes do observador (HIROMOTO, 2004, p. 45).
\end{abstract}

Oldenburg aproxima o ser humano dos objetos. A arte se inspira no cotidiano da humanidade. $\mathrm{O}$ artista coloca o enunciatário diante de questões sobre o mundo que o cerca. 
A forma amolecida de Soft Toilet aflora sentimentos e emoções e como a autora coloca, a obra evidencia o aspecto erótico e amplia os horizontes do observador. A autora ainda continua escrevendo em seu texto que essas esculturas macias, maleáveis adquirem uma conotação fálica, uma carga erótica, que associa os objetos aos órgãos sexuais, como os seios, os genitais masculinos e femininos.

\title{
3. Duchamp e Oldemburg: Uma conversa poética entre objetos
}

Os dois artistas, Duchamp e Oldemburg têm uma relação de interesse pelos objetos banais industrializados. Suas obras têm uma relação muito próxima entre a arte e a vida. Os objetos do cotidiano transformam-se e ganham um novo significado. Moraes (2002) escreve sobre essa ressignificação dos objetos, esse inesgotável poder de imigração:

\begin{abstract}
Uma vez liberados de suas aparências, de suas propriedades físicas e de suas funções, os objetos passam a ser dotados de um inesgotável poder de migração. Instaura-se uma atmosfera de indeterminação e de incerteza que evoca um tempo primeiro, quando as coisas não conheciam estados definitivos, não havia oposições nem contrários. Um tempo de incessantes metamorfoses (MORAES, 2002, p.76).
\end{abstract}

As obras são carregadas de questionamentos, fazendo o espectador pensar sobre sua vida, sobre o valor e a definição da arte. Bourlot (2010) escreve sobre a importância dos Redymade de Duchamp no movimento artístico da Pop Art, o qual Oldemburg fez parte:

\footnotetext{
El dadaísmo, al igual que el posterior movimiento pop, cuestionaba el término tradicional del arte y trató como temas el insultó y la conmoción. Es importante entonces destacar como precursor del arte pop el ready-made dadá por el cual los objetos se utilizan con un fin artístico y dejan de tener utilidad: el arte se convierte

entonces en algo cotidiano, y lo cotidiano (las latas de sopas Campbell o las cajas de brillo de Warhol, como ejemplo) (BOURLOT, 2010, p. 93).
}

No plano de expressão das duas obras encontramos obviedade, mas no plano de conteúdo referente ao significado do texto é encontrada sutileza. Kátia Canton já falou no sentido das obras contemporâneas:

Artistas contemporâneos buscam sentido. Um sentido que pode estar alicerçado nas preocupações formais que são intrínsecas à arte e que se sofisticam no desenvolvimento dos projetos modernistas do século 20 , mas que finca seus valores na compreensão (e apreensão) da realidade, infiltrada nos meandros da política, da economia, da ecologia, da educação, da cultura, da fantasia, da afetividade (CANTON, 2000, p.30).

Tanto para Duchamp como para Oldenburg, a função da obra é estética e o observador ao mesmo tempo em que reconhece o objeto do cotidiano, é surpreendido pela 
impossibilidade de uso. Ao final dessas análises, verificamos que as duas esculturas têm muita coisa em comum: o tema e os objetos industrializados do cotidiano. As autoras Krauss (1998) e a Hiromoto (2004) afirmaram que podemos perceber um subtexto erótico nas duas obras, mas que também há diferenças: Duchamp apropria-se de objetos prontos e Oldenburg subverte a função do objeto, apresentando ao público formas amolecidas. Assim, observando os procedimentos relacionais, a obra do enunciador Duchamp é natural e do enunciador Oldenburg é artificial.

Nessas duas obras, o enunciador e o enunciatário não têm uma relação tranquila. Nas duas obras, os artistas fazem o espectador pensar, refletir sobre a arte e sobre a vida. Nesse Percurso Gerativo de Sentido, nesta caminhada nada tranquila da análise das obras de artistas tão importantes para a arte no contexto mundial, é necessário que sejam retomadas por outros pesquisadores, que também se preocupam com a significação dos códigos estéticos, pois as possibilidades de acesso à significação da complexidade da imagem estética por meio da análise semiótica não se esgotam. Sem esquecer, como já escrevemos anteriormente, cada leitor vai dar significados, dependendo de seus referenciais e do seu meio.

\section{Referências}

AA.VV., Arte do séc. XX, vol. II, Köln, Taschen, 2005.

BENJAMIN, W. A obra de arte na era de sua reprodutibilidade técnica. In: Magia e Técnica, Arte e Política - Obras Escolhidas, volume 1. Trad. Paulo Sergio Rouanet. São Paulo: Editora Brasiliense, 1994.

BOURLOT, Cintia. Pop Art: ¿ El movimiento artístico de mayor cercanía con el pueblo? In: Creación y Producción en Diseño y Comunicación [Trabajos de estudiantes y egresados]. Facultad de Diseño y Comunicación. Universidad de Palermo. Centro de Estudios en Diseño y Comunicación. Centro de Producción en Diseño y Comunicación. Buenos Aires, Argentina. Año 7. Número 35. Diciembre, 2010.

BUORO, Anamélia Bueno. Olhos que pintam: a leitura da imagem e o Ensino da arte. São Paulo: Educ/ Fapesp/ Cortez, 2003.

CANTON, Kátia. Novíssima arte brasileira: um guia de tendências. São Paulo: lluminuras, 2000.

FIORIN, José Luiz. Elementos de análise do Discurso. São Paulo: Contexto, 2005. 
FLOCH. Imagens, signos, figuras - a abordagem semiótica da imagem. Cruzeiro Semiótico. Porto, jul/1985, p. 75-81.

FREUD, Sigmund. O estranho. IN: Freud, Sigmund. Obras Completas. Edição Standart. Rio de Janeiro: Imago, Vol. XXVII. 1970.

HIROMOTO, Sandra Yoshie Yamakawa. Claes Oldenburg: A poética do mole. 2004. $70 \mathrm{f}$. Monografia (Especialista) - Faculdade de Ciências Humanas, Letras e Artes da Universidade Tuiuti, Curitiba, Paraná, 2004. Disponível em:

http://www.arteparanaense.art.br/sandra_hiromoto/Claes Oldenburg.pdf. Acessado em: 23 de setembro de 2013.

KRAUSS, Rosalind. Caminhos da Escultura Moderna. São Paulo: Martins Fontes, 1998.

MC FEE, June King. Preparation for Art. São Francisco, Wadsworth Publ. Co., 1964.

MORAES, Eliane R..O corpo impossível. São Paulo: Editora lluminuras Ltd, 2002.

NÖTH, Winfried. Panorama da semiótica: de Platão a Peirce. São Paulo: Annablume, 1995. . A semiótica no século XX. São Paulo: Annablume, 1996.

ODIN, Roger. Cinéma et production de sens. Paris: Armand Colin, 1990.

OLIVEIRA, Ana Claudia de. Semioses Pictóricas. IN: OLIVEIRA, Ana Claudia de. Semiótica Plástica. São Paulo, Macker, 2004.

OLIVEIRA, Ana Claudia de; FECHINE, Yvana (eds.). Semiótica da arte: teorizações, análises e ensino. São Paulo: Hacker Editores, 1998.

OLIVEIRA, Sandra Regina Ramalho e. A leitura de imagens sob o ponto de vista da semiótica: uma crítica acerca das críticas. In: OLIVEIRA, Marilda Oliveira de. Arte, Educação e Cultura. Santa Maria: Ed. Da UFSM, 2007.

Explosão e Isotopias. Anais do IV Seminário Leitura de Imagens para a Educação: Múltiplas mídias. Florianópolis, 2011. P. 91-100. Disponível em: http://www.gpae.ceart.udesc.br/4_seminario/artigos/artigoSandraRamalho.pdf. Acessado em 21 de setembro de 2013.

O problema da leitura de imagens. Arte on line- Periódico on line de Artes. Volume 1: julho/outubro, 1999. Disponível em:

http://www.ceart.udesc.br/Revista_Arte_Online/Volumes/artigosandra.htm. Acessado em 21 de setembro de 2013. 
SCHAEFFER, Jean-Marie. A noção de obra de arte. In: OLIVEIRA, Ana Claudia. Semiótica Plástica. São Paulo, Macker, 2004.

TEIXEIRA, Lucia. Para uma leitura de textos visuais. In: BASTOS, Neusa Barbosa (org.). Língua portuguesa: lusofonia- memória e diversidade cultural. São Paulo: EDUC, 2008. P. 299-306. Disponível em:

http://www.uff.br/sedi/PDFS/2008_Teixeira_LeituraDeTextosVisuais.pdf. Acessado em 23 de setembro de 2013. 